Journal of Social and Development Sciences

Vol. 3, No. 11, pp. 374-377, Nov 2012 (ISSN 2221-1152)

\title{
Revisiting Health in Colonial Bengal: A Literary Overview (1880 -1930)
}

\author{
Tinni Goswami Bhattacharya \\ The Asiatic Society, Kolkata, West Bengal, India
}

\begin{abstract}
The essential theme of this paper is to highlight the condition of health and hygiene in the British Bengal from the perspective of official documents and vernacular writings, with special emphasis on the journals and periodicals. The fatal effects of the epidemics like malaria and cholera, the insanitary condition of the rural Bengal and the cultivated indifference of the British Raj made the lives of the poor natives miserable and ailing. The authorities had a tendency to blame the colonized for their illiteracy and callousness, which became instrumental for the outbreak of the epidemics. On the other, in the late $19^{\text {th }}$ and the beginning of the $20^{\text {th }}$, the vernacular literature played the role of a catalyst in awakening health awareness, highlighting the issues related with ill health, insanitation and malnourishment. More importantly, it became an active link between the society and culture on the one hand, and health and people on the other. The present researcher wants to highlight these opposite trajectories of mentalities with a different connotation. The ideologies of the Raj and the native political aspirations often reflected in the colonial writings, where the year 1880 was considered as a landmark in the field of public health policies. On the other, the dichotomy between the masters and the colonized took a prominent shape during 1930s. Within these fifty years; the health of the natives witnessed many upheavals grounded on the social, economic and cultural tensions.
\end{abstract}

Keywords: Bengal, Native, Health, Raj, vernacular literature

\section{Introduction}

The essential theme of this research paper is to trace a particular aspect of the socio-cultural history of twentieth century Bengal, a province under the British India, with special emphasis on the condition of health and sanitation in the late $19^{\text {th }} \&$ early $20^{\text {th }}$ century. A major part of this discourse falls within the colonial period. Hence, it is necessary to comprehend the nature of Indian society and culture, and the condition of public health in that particular colonial context. In the late $19^{\text {th }}$ century and in the beginning of the $20^{\text {th }}$, the vernacular literature along with the press played a leading part in awakening health awareness, highlighting the issues related with ill health, insanitation and malnourishment.

\section{Methods \& Procedures}

During the colonial period, the condition of public health and sanitation was not very impressive. The officials of the East India Company had a tendency to blame the indigenous people for epidemics like Cholera, malaria, plague, Kala-zar etc. As for example, in 1881 on 24th February, the Civil Medical Officer of Dinajpur, Baboo U.C. Mookherjee, wrote a letter to the Magistrate of Dinajpur, stating that,

'... Anything that contributes to the unhealthiest of a place is to be found in abundance all about Roygunge and its adjoining villages. Roygunge is almost in the centre and it is most crowded without proper roads or drains. There is a river called Kullick which except in the rains, contains throughout the year, particularly in the portion that passes through the most crowded part of Roygunge, dirty water holding all the organic impurities in most concentrated solution and, is in my opinion, unfit for use; but strange to say almost all the people use it both for drinking and cooking purposes (Arnold, 1993).

On the other hand, in the vernacular journals and periodicals, many articles were written with the aim to criticizing the British Raj for the alleged neglect of sanitary and unhygienic conditions in this regard. A critical study of the following subject cannot fail to reveal the deplorable condition of public health in Bengal, the helplessness of whose populace can be better be imagined than described. Demands to ameliorate public health conditions was voiced continually in the press, in the hosts of petitions and memorials from private 
persons in resolutions after resolutions at different annual medical conferences and in the provincial legislative council but little was done to improve public health (Bamabodhini \& Poush, 1871). Though great hopes and many expectations with regard to public health were raised after the introduction of Montagu Chelmsford Reforms (1919), there was hardly any improvement with regard to this. There was neither a clear understanding of the methods by which improvement could not be affected nor a definite program of what required to be done. Health measures had little influence on mortality and morbidity. The reports of the Director of Public Health make a melancholy reading. Even a cursory glance through the statistics in reference to deaths and diseases in these reports, give one the impression of the tremendous loss of lives due to preventable diseases. Malaria did not abate; cholera, Kala-zar and other diseases could not be stamped out. Although compulsory vaccination was introduced first in Calcutta in 1880 and gradually extended to all municipal and district board areas, Bengal continued to be a reservoir of smallpox. The rate of infant and maternal mortality was staggering (Bose, 1923).The health of the schoolchildren remained far from satisfactory. There was an acute crisis of drinking water in rural Bengal. In the urban areas, also the provision of safe drinking water was inadequate. Another fruitful source of disease and infection was to be found in the adulteration also reduced the vitality and power of resistance of an appreciable section of the population. The low standards of nutrition and of bad housing were also factors contributing to the ill health of the people. The pest of water hyacinth could not be eradicated; smoke nuisance prevailed in its worst form. A Government resolution admitted that the public health services in Bengal and India were far from developed and the problems of public health were many and varied (Bose, 1923).

This particular problem had a social approach and the structure of the society of that time was very much caste-based. Sometimes the lower-caste people had to face opposition from the upper section of the society, if they wanted to reform or uplift the existing health condition. From Sarat Chandra's 'Pandit Mosai' (The Teacher), and 'Palli Samaj' (The Village Society) we get a picture of this. Pradip Kumar Bose in his 'Health and Society in Bengal', states that, '...the examination of $19^{\text {th }}$ century Bengali periodicals dealing with matters of health and medicine and the review of the subjects and specificities of contemporary knowledge - practices discussed therein, reveal that a variety of these practices and regimes of knowledge had originally emerged in the West. These were re-situated in the course of colonial rule. The re-situation of these practices led to their reformulations as well. A different society, culture, tradition and existing indigenous knowledge - systems provided the context in which the gradual spread of this knowledge occurred, followed by its adaption and articulation through various reformulations (IBID). This particular mind-set formed a specific socio-cultural trend, which later became the pulse of the Bengali society on the verge of the $19^{\text {th }}$ and $20^{\text {th }}$ century Bengali Renaissance. From 1900 onwards, the relation between health and society became more prominent where the native mind played the role of a catalyst. As for example, in the Swasthya Samachar Patrika (B.S. 1332, Chaitra), a lecture by Rabindranath Tagore, the famous Noble Lauriat, was published under the title of 'Rabindranath and Rural Reconstruction'. Rabindranath's call for self - awakening was definitely a reflection of the enlightened Bengali psyche which spoke for self - esteem and self - enrichment, in other words, a state of self - awareness. It was commonly felt that to improve the state of health and hygiene in the country in general, and Bengal in particular; self-awareness was the most primary tool. In addition, it could result only by the spread of education. Therefore, emphasis should be put on compulsory education at primary and secondary level (IBID).

The political aspect of these writings also had an important mark. From the twentieth century onwards, the plea for reforms in the administrative machinery became a common issue. It was written in the journal Probasi (Aghrawn, 1319) that, the cultivated indifference of the British Raj and its administrative malfunction became responsible for the immense miseries of the natives (IBID). With this socio-cultural back drop, it has become quite simpler to analyze the response of the Raj forwards the health problems of the natives. It is evident from the Reports of the Sanitary Commissioner's of Bengal, the funding was inadequate all the time, and several Union and District Boards had to depend on the natives regarding any kind of development in this sector. Because of this, the tax burden increased almost every year, which created resentment largely amongst the Bengalis and became an important issue of their writings. This financial stringency was a common problem throughout the British period, and was a great obstacle for reforms. Secondly, the British Government was often hesitant to intervene in the matters of the colonized, such as health and sanitation, or other personal, private, social problem, due to the fear of opposition, from the society. This became more acute after the Revolt of 1857. The Sanitary Commissioners were aware about the fact and after expressed 
their grievances in this regard. Apart from this, as the vernacular journals, and the other literature of that time give the impression that, at times the authorities became very strict, unreasonable and harsh to implement their health policies, particularly with regard of the prevention of the epidemics like plague, cholera etc. For example, because of the quarantine policy or the compulsory inspection of the native houses, the colonized, both men and women, had to suffer to a great deal. The Health Inspectors generally carried the legal permission to enter into the women's quarters of the native houses. This was considered as an unwarranted encroachment into the private domain of the Indian household and therefore to the Indian culture and customs. Not only that, the notion of racial superiority was always there which has been termed by the historians like David Arnold as an attempt to 'colonize the body (Metcalf, 1995).

It was stated by the Epidemic Diseases Act (III of 1897) that '... (3) Any person disobeying any regulation or order made under this Act shall be deemed to have committed an offence punishable under section 188 of the Indian Penal Code. (4) No suit or other legal proceeding shall lie against any person for anything done or in good faith intended to be done under this Act (Nathan, 1996-97) (The plague In India, 1896, 1897, Simla, 1898, compiled by Nathan). It is clear from this above mentioned paragraph that, on the one hand the British Government had an intention to reform but on the other they tried to 'superimpose' their ideas on the natives which was none other than a specific form of 'dictatorship'. This dichotomy played an important role throughout the British period behind their decision-making. The power of the British having been established fully in the $19^{\text {th }}$ century, their administration was simultaneously taking a definite and coherent shape. Since early $19^{\text {th }}$ century, such ideologies like utilitarianism and Evangelicalism were deeply influencing the policies of the British Government. With the beginning of the $20^{\text {th }}$, a newer ideology, namely the 'Whiteman's Burden' materialized. This concept developed and grew on the earlier evangelical and utilitarian ideas. It was a statement of the cultural superiority of the West, of the racial superiority of the white man and therefore his Christian / racially superior duties to bring about the deliverance of the colonized / racially superior duties to bring about the deliverance of the colonized / nonwhite people in cultural, material contexts (Dinagpore, 1881).

The British considered India as a 'land of dirt, disease and sudden death'. To them, India with its unfamiliar topography, unbearable climate, 'unknown plant and animal life' was 'an exotic and dangerous space'. From this developed the British concepts of 'tropical climate' and 'tropical diseases, and the 'vision of India as a land of peril', where they had to live 'at their peril'. While they devised strategies and methods to ensure a greater degree of survival in its climate, they also developed a way to put the blame about the prevalent diseases and deplorable health conditions of the country not just on its climate 'but on Indian fatalism, inertia and superstition'. Taking cholera as a case, it was considered a typically Indian disease and closely related to Hindu superstition. The British disgust at the native devise of imputing deliverance from the disease upon a particular goddess is an example of Hindu fatalism. It is to be noted that both cholera and malaria so arguably linked with the 'tropical' concept actually happened in a regular manner in temperate regions of Europe and England too with the exception of Ireland (Probasi, 1319). During this period, at the onset of the specific colonial mentality, the native women of Bengal also became aware about their health which was reflected in many of their writings. As for example, in Bamabodhini Patrika, one Shree Laxmimani wrote a poem on the Burdwan fever. Here she described the fatal effects of a special kind of ailment which once took the form of an epidemic in the district of Burdwan of the Bengal province. She highlighted the sufferings of the poor natives and the unavailability of the western medicine, furthermore accelerated the pace of the crisis (Ray, 1998). During the colonial rule, there was always a tendency on the part of the rulers to blame the Indians for their ignorance, but very few people had the courage to point out the faults of the Government regarding this. In 1923, in an article, published in 'The Calcutta Review', the famous geological, Pramathanath Bose wrote 'It is not ignorance of hygiene, but hygienic reform on western lines, not death of academically trained midwives and medical men, but dearth of nutritious, suitable food, or wholesome drinking water, of pure air, of free drainage, of tranquility of mind, and indulgence in tea, alcohol, manufactured medicines, cigarette, etc., that is sapping the vitality of our people and reducing their capacity for resisting or overcoming the attacks of malaria and other diseases (Ray, 2009). Apart from criticizing the authorities and the western civilization, the writer also had taken an attempt to find out the faults within the native society and perhaps wrote with a heavy heart, wrapped with the notion of confession, - 'Nobody is to be blamed, Shyama (The Goddess Kali), we drown in the deep waters of the cesspool dug by ourselves. ${ }^{14}$ This quotation aptly describes the self - appraisal of the educated Bengalis, who were of the whole situation. 


\section{Conclusion}

From the above-mentioned discussion, it is evident that, the writings of colonial Bengal, both official and vernacular, were an example of the colonial mentality as well as the desire to attain freedom. Here the concern for health and hygiene played the role of a metaphor. The fifty years from 1880-1930 was a transitional period witnessing numerous upheavals grounded on the social, economic, political and cultural tensions. The year 1880 became a landmark, as it saw the first sign of decentralization in the field of public health policies with the creation of the post of Deputy Sanitary Commissioner. On the other, the year 1930 was on the eve of the Indian independence (1947), representing the Indian vigor and colonial apathy. It was a period, when the natives started to intervene in the administration with their innovative ideas. These people along with the authors of the vernacular journals and periodicals gave birth to a specific trend, which later became a culture based on the indigenous society. The native plea for self-rule often collared with the desire of having a better place for living. The Bengali intelligentsia through their writings had taken an attempt to challenge the established colonial perception of the British masculinity and Indian femininity, particularly the impotency of the Indian male. Here the printing media became instrumental to create an open public forum against the Raj with special emphasis on the vernacular. Both the official and the other writings of the colonial era on health and hygiene perhaps focused on two things. Firstly, the cultivated indifference of the Government often accelerated the velocity of the crisis. Secondly, the indigenous society, bounded with religious superstitions and irrational customs often posed an obstacle for reforms. This stance was very much prominent in the writing of Pramathanath. The notion of self -criticism along with the nationalistic aspirations became an important component of the native mentality during the colonial period. Lastly, the European concepts of health and hygiene often amalgamated with the traditional ideas particularly, those on the Ayurveda (Ancient Hindu Medical Text). This fusion was very much apparent in the vernacular health journals of that time. It created a new kind of consciousness amongst the colonized regarding health and hygiene. Even the women of Bengal, both Hindu and Muslim, raised their voice in favour of indigenous system. Begum Rokeya, the pioneer in the field of Muslim women's emancipation, wrote to support the traditional medicine along with the western line of treatment. This particular trend even reflected in the official writings. Situating all these, it can be said that, it is not an easy task to re-experience the colonial health. However, there is no harm to do so with the help of the contemporary literature. From which we can get the glimpses of the past.

\section{References}

Arnold, D. (1993). Colonizing The Body, Oxford, 1993, passim.

Bamabodhini, P. \& Poush, B. S. (1871). 1278, A.D. 1871

Bose, P. K. (2006). Health and Society in Bengal, A selection from late $19 \mathrm{~m}$. Century Bengali Periodicals, Sage, New Delhi, 2006, Introduction, 10-46.

Bose, P. (1923). Fifty-Eight years Fight with Malaria published. The Calcutta Review, III, 98.

Metcalf, T. R. (1995). Ideologies of the Raj, Cambridge University Press, Preface - IX.

Nathan, R. (1896). The plague In India, 1896, 1897, vol-II, Simla 1898, Appendix IV.

No. 74 dated Dinagpore. (1881). the $24^{\text {th }}$ February 1881, From Baboo U.C. Mookherjee M.B.C.M. Civil Medical Officer of Dinagpore.

Probasi, A. (1319). B.S. 1319, A.D.1912.

Ray, K. (1998). History of Public Health, Colonial Bengal 1921-47, K.P. Bagchi and Co., Calcutta, 1998, Chapter XII, 343-348.

Ray, K. (2009). Press and Public Health Bengal 1921-47, Corpus Research Institute Kolkata, 2009, Introduction. Swasthya Samachar Patrika, B.S.1322, A.D. 1915 